\title{
PANORAMA ACTUAL DE LOS ENSAYOS CLÍNICOS EN EL PERÚ
}

\author{
CURRENT SITUATION OF CLINICAL TRIALS IN PERU
}

Uriel García-Cáceres ${ }^{1, a}$

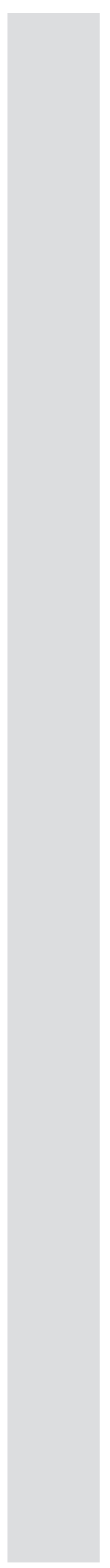

La historia de la medicina, nacional y mundial se encuentra enaltecida o manchada, según sea el caso, con ejemplos de utilización de seres humanos para realizar investigación científica. Por ejemplo, los llamados "ensayos clínicos" con el fin de averiguar la eficacia de medicamentos nuevos, esos que recién han sido descubiertos y están en proceso de ser patentados e industrializados. En su inmensa mayoría esos productos son elaborados en países desarrollados por compañías farmacéuticas multinacionales que, para lograr la inscripción en sus países de origen, utilizan a seres humanos de distintos países.

Conviene tener una perspectiva histórica sobre el uso de humanos para estudios a través de los tiempos. Las más modernas reglas de protección a los seres humanos durante los ensayos clínicos comenzaron a fines de la década de 1970, en los Estados Unidos, las que tuvieron repercusión mundial. Esto ocurrió después que se descubrió el tristemente célebre caso del Estudio Tuskegee sobre sífilis no tratada en varones negros. Dicho trabajo fue conducido por investigadores del National Institutes of Health de los EE. UU., de 1932 a 1978. Un miembro de esa institución alertó a los medios de comunicación para difundir los pormenores del experimento en el cual se usaron 600 ciudadanos varones afroamericanos, iletrados y sifilíticos de la ciudad Tuskegee, en el estado de Tennesse; estas personas fueron reclutadas para observar la evolución de la sífilis sin tratamiento, hasta la muerte. Con ello se demostró en publicaciones médicas sucesivas la "historia natural de la sífilis" (1).

Este "experimento" se equipara en crueldad al del malariólogo alemán Klauss Karl Shilling (1871-1938), quien practicó "ensayos clínicos" con drogas antimaláricas en los prisioneros del campo de concentración de Dachau, durante la Segunda Guerra Mundial, por ello Shilling fue ahorcado en Nuremberg. En EE. UU. nadie fue colgado por el experimento de sífilis, pero en julio de 1997 el presidente Clinton pidió disculpas a nombre de la Nación, e invitó a la Casa Blanca a tres de los reclutados en aquella época, quienes ya estaban ancianos. Solo acudieron dos, ya que el tercero estaba agónico, para mostrar al mundo los cambios que la sífilis les produjo durante cuarenta años a consecuencia de la experimentación.

Hay que partir de la premisa que en la ciencia biomédica es indispensable el uso de humanos para experimentación científica. Daniel Alcides Carrión, como dijo Lawren Ackeman (2-3), postuló para el mundo entero el principio de bioética de que el primero que debe entrar a la experimentación es el propio investigador. Hasta ahora hay seguidores de ese principio que permitió, por ejemplo, la cateterización del corazón en su propio cuerpo, por Werner Frossmann, en 1929. Por otro lado, es comprensible que una buena práctica científica tiene que basarse en cantidades de sujetos y experimentos estadísticamente significativos, cuando se trata de estudiar reacciones producidas por medicamentos.

El Informe Belmont ${ }^{(4)}$, toma dicho apelativo por el "Centro de Convenciones Belmont" en el distrito Bethesda, Maryland en EE. UU.; lugar donde se reunieron los expertos más connotados por mandato de una ley federal de ese país, con el fin de crear normas y organismos encargados de verificar la veracidad de los experimentos científicos y la protección de los derechos de los sujetos de experimentación, teniendo en cuenta que la especie zoológica usada pertenece al género Homo sapiens. Especie que para algunos posee molestos derechos que deben respetarse y protegerse. El resultado inmediato del Informe Belmont fue la creación de The National Commission for the Protection of Human Subjects of Biomedical and Behavioral

Academia Nacional de Medicina. Lima, Perú.

Editor invitado de la RPMESP, médico patólogo doctor en Medicina

Recibido: 19-11-12 Aprobado: 28-11-12

Citar como: García-Cáceres U. Panorama actual de los ensayos clínicos en el Perú. Rev Peru Med Exp Salud Publica. 2012;29(4):427-8. 
Research. Esta comisión, junto con otros instrumentos derivados de ella, se encarga de cumplir los mandatos de la Ley en los Estados Unidos.

Conseguir voluntarios humanos para los ensayos clínicos en los Estados Unidos, la Comunidad Europea o Japón, es muy difícil y costoso. En otros países resulta más fácil, sobre todo en los que la investigación biomédica todavía es incipiente por la ausencia de industrias farmoquímicas y por que en algunas universidades estatales apenas se está pisando las más avanzadas fronteras de la ciencia biomédica.

En el 2006, el Ministerio de Salud del Perú a cargo de la Dra. Pilar Mazzetti, promulgó las primeras disposiciones que reglamentan los ensayos clínicos, inspirados en el Informe Belmont, y se encargó al Instituto Nacional de Salud la organización y reglamentación de dicho documento. Desafortunadamente, los conflictos de interés hacen peligrar el desarrollo de una política clara y transparente en la ejecución de estos. Se necesita que las instituciones representativas que actualmente defienden los intereses de la población, como la Defensoría del Pueblo e INDECOPI, estén representadas en los comités que autoricen la realización de ensayos clínicos en seres humanos, en el Perú.

Este número de la Revista Peruana de Medicina Experimental y Salud Pública, está dedicado a exponer el estado actual de los ensayos clínicos. En el simposio presentado en esta edición se cuenta con la contribución de la Dra. Pilar Mazzetti, neurogenetista y ex ministra de salud, quien expone sobre el rol del Estado en la regulación de los ensayos clínicos como parte de su experiencia en la elaboración de las primeras reglamentaciones en ensayos clínicos en el Perú. También se cuenta con la contribución del Dr. Duilio Fuentes, médico internista quien junto con el equipo responsable de la conducción del Registro Nacional de Ensayos Clínicos en el Instituto Nacional de Salud de Perú, presentan el panorama actual de regulación de ensayos clínicos del país. Es destacable la contribución del Dr. Andrés Bayona, médico internista y presidente de la Asociación Peruana de Organizaciones de Investigación Clínica por Contrato, quien presenta un artículo dedicado a señalar potenciales beneficios y oportunidades para el Perú que trae el desarrollo de nuevos medicamentos. De otro lado, el Dr. Germán Málaga, médico internista, investigador y docente universitario de la Universidad Peruana Cayetano Heredia, discute sobre si los ensayos clínicos desarrollados en el Perú realmente contribuyen con el desarrollo de investigaciones orientadas a los problemas de salud en nuestro país. Por último, el Dr. Eduardo Rodríguez, doctor en biología e investigador de la Universidad de Chile, nos expone potenciales retos y desafíos de la investigación preclínica, que a veces lleva a la necesidad de construir modelos animales con manipulación genética.

Estas importantes contribuciones serán útiles en el diseño de una política de estado para que la investigación biomédica usando seres humanos, indispensable por cierto, se realice para asegurar el progreso científico con protección de los derechos de las personas sometidas a la experimentación, sean sanas o enfermas.

\section{REFERENCIAS BIBLIOGRÁFICAS}

1. Center for Disease Control and Prevention. U.S. Public Health Service Syphilis Study at Tuskegee [Internet]. Atlanta, GA: CDC; [citado el 13 de noviembre dl 2012]. Disponible en: http://www.cdc.gov/ tuskegee/timeline.htm
2. Altman LK. Who goes first? The story of self-experimentation in medicine. New York: Random House; 1987.

3. Garcia-Caceres U, Garcia FU. Bartonellosis. An immunodepressive disease and the life of Daniel Alcides Carrión. Am J Clin Pathol. 1991;95(4 Suppl 1):S58-66.
4. The National Commission for the Protection of Human Subjects of Biomedical and Behavioral Research. The Belmont report: ethical principles and guidelines for the protection of human subjects of research. Washington, DC: U.S. Government; 1975. 